\title{
Functionalization of terminal carbon atoms of hydroxyl terminated polybutadiene by polyazido nitrogen rich molecules
}

\author{
RAJAVELU MURALI SANKAR, TAPTA KANCHAN ROY and TUSHAR JANA* \\ School of Chemistry, University of Hyderabad, Hyderabad, India
}

MS received 3 March 2010; revised 19 August 2010

\begin{abstract}
We report a novel synthetic approach for the attachment of the polyazido nitrogen rich molecule on to the hydroxyl terminated polybutadiene (HTPB) backbone. The terminal carbon atoms of the HTPB are functionalized by attaching cyanuric chloride (CYC) covalently on the HTPB backbone. Further reaction of this modified HTPB with sodium azide yields polyazido nitrogen rich HTPB. The unique physico-chemical properties and the microstructure of the HTPB do not get affected upon modification. IR, gel permeable chromatography (GPC) and absorption spectroscopy studies prove that the polyazido nitrogen rich molecules are covalently attached at the terminal carbon atoms of the HTPB. The $\pi$ electron delocalization owing to long butadiene chain, strong electron withdrawing effect of the triazine molecules are the major driving forces for the covalent attachment of the triazine at the terminal carbon atoms of the HTPB. The disruption of the intermolecular hydrogen bonding between the terminal hydroxyl groups of the HTPB chains and the presence of hydrogen bonding between the $N$ atoms of the triazine ring with OH group of the HTPB are observed. Theoretical study also reveals the existence of the hydrogen bonding between the $\mathrm{OH}$ and $\mathrm{N}$. Theoretical calculation shows that the detonation performance of the polyazido nitrogen rich HTPB are very promising.
\end{abstract}

Keywords. Polybutadiene; functionalization of polymers; energetic binder; hydrogen bonding.

\section{Introduction}

Composite propellants are cross-linked polyurethanes prepared from a mixture of low molecular weight prepolymer, solid energetic materials and plasticizer (Urbanski 1984). This low molecular weight prepolymer is often called as binder. The binder helps the processing of the energetic materials and provides the required mechanical strengths to the final composition of the propellant (Kit and Evered 1960; Urbanski 1984; Desai et al 1996). Hydroxyl terminated polybutadiene (HTPB) is being used as binder for the modern high performance composite propellants because of its unique physico-chemical properties such as excellent flow characteristics and storage capacity compared to other known binders (Murray and Purves 1940; Meyers and Baumgarter 1973; Muthiah et al 1991). Several commercially available explosives are used with the HTPB in propellant formulation (Mathieu and Stucki 2004). Several authors have studied the shock response behaviors of the HTPB polyurethane with and without energetic materials (Bohn and Elsner 1999; Millet et al 2004; Millet and Bourne 2004). The excellent shock absorbing capacity of the HTPB polyurethane drastically reduces the sensitivity and vulnerability of the explosive

\footnotetext{
*Author for correspondence

(tjsc@uohyd.ernet.in; tjscuoh@gmail.com)
}

materials. HTPB based polyurethanes have also been studied by several authors for the separation of organic compounds (Gupta et al 2002), for selective adsorption of proteins (Yang and Lin 2001) and for selective gas transport properties (Chen et al 2000). Recently, HTPB was been successfully used for the fabrication of elastic conducting polymer micro-particles with core-shell structure (Kuo et al 2003). HTPB has three different types of microstructures (e.g. cis, trans, vinyl) and their relative percentage of microstructure in a given sample depends upon the polymerization condition by which it was synthesized. The flow characteristics of the HTPB and the mechanical properties of the corresponding polyurethane depend upon the quantity of microstructure present in the sample. The viscosity of the HTPB increases with increase in vinyl content and the mechanical properties such as tensile strength, percentage elongation of the corresponding polyurethane show significant improvement with increasing trans content and decreasing vinyl content (Manjari et al 1993; Nazare et al 1993). A lot of effort has been made for the determination and evaluation of the microstructure of the HTPB using various techniques such as IR, ${ }^{1} \mathrm{H}$ NMR, ${ }^{13}$ C-NMR, etc (Zymonas et al 1973; Quack and Fetters 1978; Hardwood 1982; Kanakavel 1987).

There are some unavoidable problems in using HTPB as a binder despite its excellent physical properties and ability to reduce the vulnerability of explosives. HTPB dilutes the explosive by reducing the overall energy out- 
put since it is inert in nature. HTPB can load maximum $92 \%$ solid energetic materials and rest of the $18 \%$ in the propellant formulation is inert binder which reduces the overall energy output of the propellant. Till now this inert binder was being used in the explosive composition. Therefore, there is a need for the development of an energetic binder by introducing energetic functionality into the inert binders. Several attempts have been made to develop the energetic binders. Among this glycidyl azide polymer (GAP), poly (3-nitratomethyl-3-methyloxetane) (Poly NIMMO), poly (glycidylnitrate) (Poly GLYN), polyvinyl nitrates, etc are notable (Vandenberg 1972; Golding et al 1988; Gaur et al 2003). Unfortunately, it turns out that these binders have several limitations for their use in the propellant formulation. Therefore, till now HTPB is the first and best choice for propellant formulation despite the availability of these new energetic binders. Thus, it is clearly seen that there is a tremendous scope to develop energetic HTPB by introducing energetic functionality on it without destroying its excellent physico-chemical properties. A significant number of efforts have been demonstrated in the literature to attach the energetic functionality onto the HTPB backbone (Eroglu et al 1996; Paul 1997; Subramanian and Sastri 2003). Two different reaction pathways are employed to nitrate the HTPB backbone. It has been observed that up to $10 \%$ nitration on the HTPB backbone gives a good balance of energy output, mechanical properties and miscibility with energetic plasticizers (Paul 1997). The energetic polymer poly (glycidyl azide) has been grafted on to the HTPB (Eroglu et al 1996). Recently, iron was coordinately linked to the HTPB backbone to enhance the burn rate of the composite solid propellant (Subramanian and Sastri 2003). Despite these attempts none of these methods were able to replace the use of HTPB in propellant. In our previous article, we have reported the functionalization of the HTPB backbone with an energetic molecule, 2,4dinitrobenzene (density $=1.60 \mathrm{~g} / \mathrm{cc}$, detonation pressure $=15.06 \mathrm{GPa}$, velocity of detonation $=6.05 \mathrm{~km} / \mathrm{s}$ ) (Muralisankar et al 2009a). In continuation of our efforts to develop energetic binder, we have attempted to attach a polyazido nitrogen rich molecule on to the HTPB backbone. Polyazido nitrogen rich molecules are well known explosives because of their very high heat of formation (Huynh et al 2004). However, their applications are very limited owing to their extreme sensitivity to spark, friction and impact (Huynh et al 2004). Recently, polyazido nitrogen rich molecules were functionalized by azo (Huynh et al 2004) and substituted pyrazole (Ye et al 2007) linkages to produce stable energy rich molecules. In this article, we report the modification of HTPB backbone by covalently attaching an energetic molecule 1-chloro3,5-diazido-2,4,6-triazine (CDT, scheme 1) at the terminal carbon atoms of the HTPB. We have characterized the functionalized HTPB using IR, NMR, and UV-Vis, etc and calculated their detonation performance theoretically.

\section{Experimental}

\subsection{Materials}

HTPB was prepared by free radical polymerization using hydrogen peroxide as initiator (HEMRL Pune, India). Sodium hydride $(\mathrm{NaH})$ and sodium azide $\left(\mathrm{NaN}_{3}\right)$ were purchased from LOBA chemical, India. The cyanuric chloride (CYC) was purchased from Sigma-Aldrich. All the solvents (chloroform, tetrahydrofuran, dichloromethane) were dried and distilled before use. NMR solvents were obtained from Merck, India.

\subsection{Functionalization of HTPB with CYC}

$3.299 \mathrm{~g}$ (61 mmol, considering 54 as the molecular weight of HTPB repeat unit) of moisture free HTPB was taken in $10 \mathrm{ml}$ of dichloromethane solvent in a three neck round bottom flask fitted with a guard-tube and continuous nitrogen purging. HTPB was completely dissolved in dichloromethane solvent by stirring with a magnetic stirrer. $0.223 \mathrm{~g}(10 \mathrm{mmol})$ of $\mathrm{NaH}$ was added to the HTPB solution in presence of continuous nitrogen gas purging. The mixture was stirred for $30 \mathrm{~min}$ and then the cyanuric chloride $(0.184 \mathrm{~g}, 1 \mathrm{mmol})$ was added to the reaction mixture. The stirring was continued for another $3 \mathrm{~h}$ in presence of nitrogen gas purge and then continued overnight without nitrogen gas. The solvent was removed at $50^{\circ} \mathrm{C}$ in rotary evaporator. The resulting product was washed thoroughly and repeatedly with methanol followed by hexane to remove the traces of the $\mathrm{NaH}$, unreacted CYC and excess HTPB. The final compound was milky white in color which is different from the parent HTPB. The purity of the resulting sample was checked by thin layer chromatography (TLC) using $3: 2(\mathrm{v} / \mathrm{v})$ mixture of hexane and ethyl acetate as a solvent. The reaction scheme for the modification of HTPB is presented in scheme 2 .

\subsection{Preparation of $H T P B-D T$ from $H T P B-C Y C$}

$2 \mathrm{~g}(5.7 \mathrm{mmol}$; considering 348 as the molecular weight of HTPB-CYC repeat unit) of moisture free HTPB-CYC<smiles>Nc1nc(N)nc(N)n1</smiles>

Scheme 1. Chemical structure of polyazido nitrogen rich molecules; (1) cyanuric azide (2,4,6-triazido-1,3,5-triazine) and (2) 1-chloro-3,5-diazido-2,4,6-triazine (CDT). 
was dissolved in $10 \mathrm{ml}$ THF solvent and taken in a separating funnel. A solution of sodium azide $(0.054 \mathrm{~g}$, $0.83 \mathrm{mmol}$ ) in $5 \mathrm{ml}$ water was added to the HTPB-CYC solution in the separating funnel and mixed thoroughly for $5 \mathrm{~min}$ to prepare the HTPB-DT compound. The organic phase was separated by using dichloromethane solvent and the solvent was evaporated at room temperature. The final product (HTPB-DT) was obtained as a fluidic material (viscosity $=2360 \mathrm{cp}$ ). The purity of the resulting sample was checked by thin layer chromatography (TLC) using $3: 2(\mathrm{v} / \mathrm{v})$ mixture of hexane and ethyl acetate as a solvent. The reaction scheme for the HTPBDT preparation is presented in scheme 2 .

\subsection{Characterization of the functionalized HTPB}

The molecular weights and molecular weight distributions of the samples (HTPB, HTPB-CYC and HTPBDT) were determined by Gel Permeable Chromatography

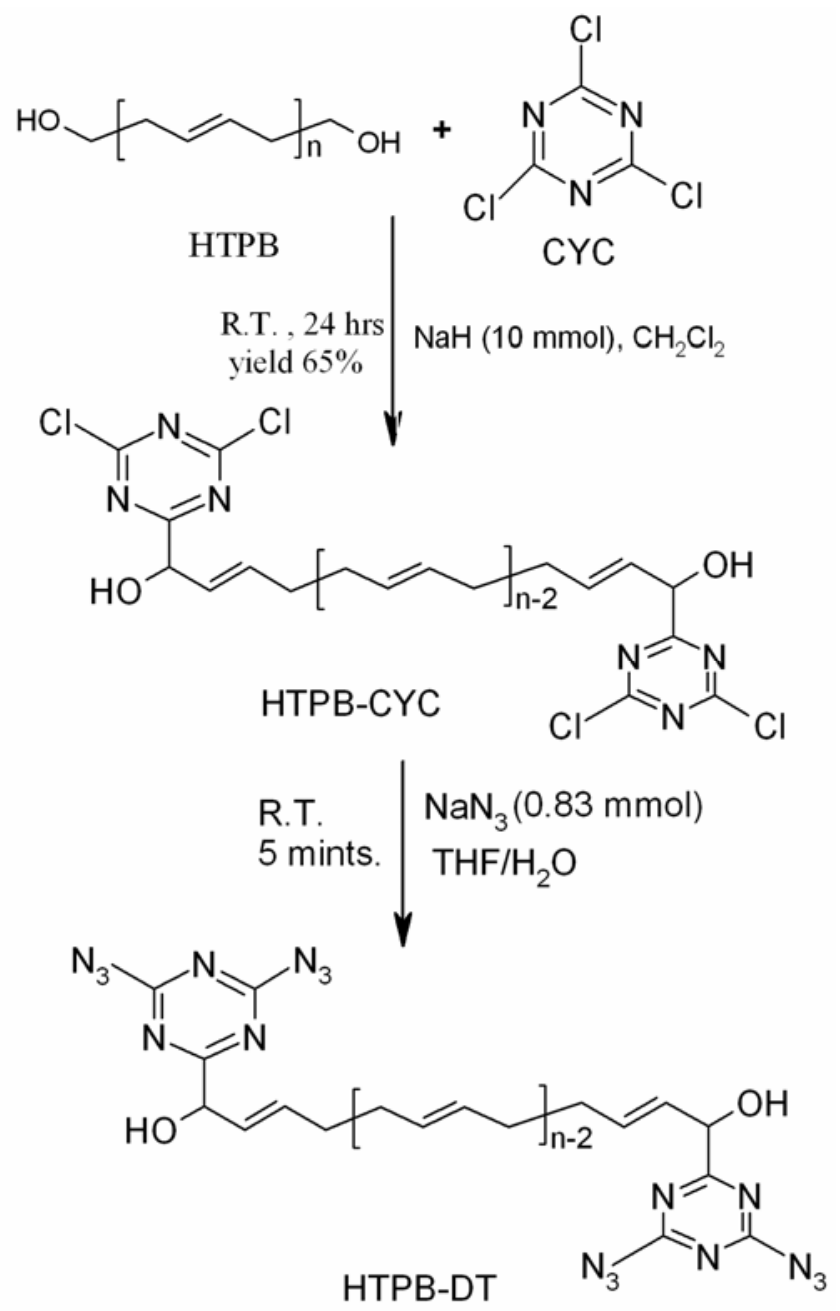

Scheme 2. Terminal functionalization of HTPB by polyazido nitrogen rich molecules.
(GPC) using Agilent GPC 1100. The Agilent pump was equipped with three polymer standard in series (two $100 \AA$ and one $1000 \AA$ columns) and an Agilent 1100 series RI detector. THF was used as the eluent at a flow rate of $1.0 \mathrm{ml} / \mathrm{min}$. Polymer solution $(0.2 \mathrm{wt} \%)$ in THF was used for the analysis. Molecular weight of the polymers was calculated using PSS software (PSS Win GPC scientific $\mathrm{V}$ 6.10) against linear low polydispersity polystyrene standards. FTIR spectra of the HTPB, HTPBCYC and the HTPB-DT were recorded on a Nicollet 4700 FT-IR spectrometer. The spectra were taken using neat samples in $\mathrm{KBr}$ crystal. The ${ }^{1} \mathrm{H}-\mathrm{NMR}$ and ${ }^{13} \mathrm{C}$-NMR of the samples were recorded on a Bruker $400 \mathrm{mHz}$ spectrometer using $\mathrm{CDCl}_{3}$ as a solvent. The UV-Vis absorption spectra of the dilute solution of the sample in THF solvent were recorded on a Cary-100Bio (VARIAN) spectrophotometer. The hydroxyl values of the samples were determined by acetylation method using pyridine and acetic anhydride as a reagent mixture (Ogg et al 1945). The viscosity was determined using Brookfield viscometer (DV-III Ultra model).

\subsection{Computational details for theoretical study}

All the quantum mechanical calculations were performed with the Gaussian 03 program package (Frisch 2003). The Becke three-parameter hybrid (B3) functional was used along with Lee-Yang-Parr (LYP) correction (Lee et al 1988; Becke 1993). The 6-31g* basis set is employed in all calculations reported here. Vibrational frequencies were calculated to characterize the stationary points and zero-point vibrational energy (ZPVE) corrections.

\section{Results and discussion}

\subsection{Functionalization of HTPB}

Polyazido nitrogen rich molecules such as cyanuric azide (2,4,6-triazido-1,3,5-triazine, scheme 1) possess very high heat of formation because of the energetic azido groups in the molecule. The presence of large number of energetic $\mathrm{N}-\mathrm{N}$ and $\mathrm{C}-\mathrm{N}$ bonds are responsible for high heat of formation (Huynh et al 2004). These nitrogen rich molecules form a unique class of energetic materials. Based on the above observation, we hypothesized that the attachment of polyazido nitrogen rich compound on to the HTPB, a well known binder for propellant, backbone will produce an energetic binder. However, attachment of cyanuric azide on HTPB is impossible because the former does not have the required functional group for the attachment chemistry. Earlier, we have demonstrated that molecules with very strong electrophilic nature can be easily attached on to the HTPB terminal carbon atoms (Muralisankar et al 2009a). We have covalently attached 
2,4-dinitrochlorobenzene (DNCB) in the HTPB backbone. The presence of nitro groups makes $\mathrm{Cl}^{-}$a very good leaving group and as a result DNCB shows very strong electrophilic nature (Muralisankar et al 2009a). Therefore, based on our precedence and our intention to attach polyazido nitrogen rich molecule we decided to attach 1chloro-3,5-diazido-2,4,6-triazine (CDT, scheme 1) on to the HTPB backbone. CDT molecule possesses both $\mathrm{Cl}$ and azido functionality which makes it suitable for attachment chemistry as well as it exhibits energetic properties as discussed later. Hence, by attaching the CDT on to the HTPB we expect to produce an energetic binder for propellant application. Our theoretical calculation (discussed later) shows that the heat of formation of CDT is $1085.82 \mathrm{~kJ} / \mathrm{mol}$ which is similar to that of cyanuric azide (1053 kJ/mol) (Huynh et al 2004). Also, our calculation reveals that the detonation performance of CDT is higher than the well known energetic material, trinitrotoluene (TNT). Hence CDT is a superior energetic class material.

The prime hurdle to attach CDT on to HTPB is the availability of CDT molecule. CDT is a poor thermally stable molecule and hence it is difficult to synthesize. Moreover, handling of CDT is extremely dangerous since most of the polyazido nitrogen rich compounds are infamous for their extreme sensitivity to spark, friction and impact (Huynh et al 2004). We have developed an alternate synthetic method for the attachment of the CDT molecule to the HTPB polymer backbone which does not require the synthesis of CDT molecule. Cyanuric chloride (CYC) have covalently attached at the terminal carbon atoms of the HTPB polymer backbone (scheme 2) (Muralisankar et al 2009b). The modified HTPB (HTPBCYC hereafter) has been further reacted with $\mathrm{NaN}_{3}$ to get the azide substitution at the 3,5 position of the attached cyanuric chloride by replacing the chlorine from the CYC moiety (scheme 2). This azide substitution changes the CYC moiety to CDT moiety which is our desired molecule. Hereafter we defined this molecule as HTPB-DT. In the later section, we have carried out theoretical analysis of the HTPB-DT which shows that the modified HTPB is an energetic binder. Since the CDT molecule is not stable, it is impossible to synthesis and difficult to handle; therefore first we have attached the CYC into the HTPB backbone and then functionalized with azide group to prepare the HTPB-DT molecule. The covalent attachment of the CYC on to the HTPB backbone is carried out using $\mathrm{NaH}$ as a catalyst in $\mathrm{CH}_{2} \mathrm{Cl}_{2}$ solvent by taking appropriate moles of the HTPB and the CYC. After a careful and thorough purification of the HTPB-CYC compound it is subjected to various characterization processes and further reacted with $\mathrm{NaN}_{3}$ to get HTPBDT. The catalyst $\mathrm{NaH}$ plays an important role for the covalent attachment of CYC molecule in the HTPB backbone. The absence of any kind of functional group at the terminal carbon atoms (except hydroxyl group) makes it difficult to carry out the attachment chemistry. However, we have seen earlier (Muralisankar et al 2009a, b) that the $\mathrm{NaH}$ catalyst can help the covalent attachment of highly electrophilic molecule on to the HTPB backbone. The detailed mechanism will be explained in the next section.

All the samples (HTPB, HTPB-CYC and HTPB-DT) were characterized using FT-IR, ${ }^{1} \mathrm{H}$ and ${ }^{13} \mathrm{C}$ NMR spectroscopy techniques. The presence of $\mathrm{C}=\mathrm{C}$ vibration $\left(1641 \mathrm{~cm}^{-1}\right)$ and the microstructures (968 for 1,4 trans, 911 for 1,2 vinyl and 721 for 1,4 cis) (Nazare et al 1993) of HTPB are clearly visible in all three cases (figure 1). These observations hint that the double bond and the microstructures of the butadiene have not been disturbed even after the modification of the polymer backbone. The peak at $550 \mathrm{~cm}^{-1}$ in case of HTPB-CYC is due to $\mathrm{C}-\mathrm{Cl}$ vibration (Silverstein and Webster 2002) and the absence of $\mathrm{C}-\mathrm{Cl}$ vibration in case of HTPB-DT indicates that both the $\mathrm{Cl}$ atoms in the HTPB-CYC have been replaced by the azide groups. Also, the presence of azide group is evident from the peaks at 2364 and $2132 \mathrm{~cm}^{-1}$ in HTPBDT (Silverstein and Webster 2002). The $\mathrm{O}-\mathrm{H}$ frequency due to terminal hydroxyl group comes at 3407 for HTPB and $3463 \mathrm{~cm}^{-1}$ for HTPB-CYC and HTPB-DT (Subramanian et al 1999). Therefore, it is clearly evident that the free terminal hydroxyl groups are intact after the modification of HTPB backbone. The hydroxyl value of all these samples are measured and listed in table 1 . The hydroxyl values in all the cases are similar and this once again strengthens our observation from the IR studies that the free $\mathrm{OH}$ groups are available in the modified HTPB (HTPB-CYC, HTPB-DT) for further reaction. The free

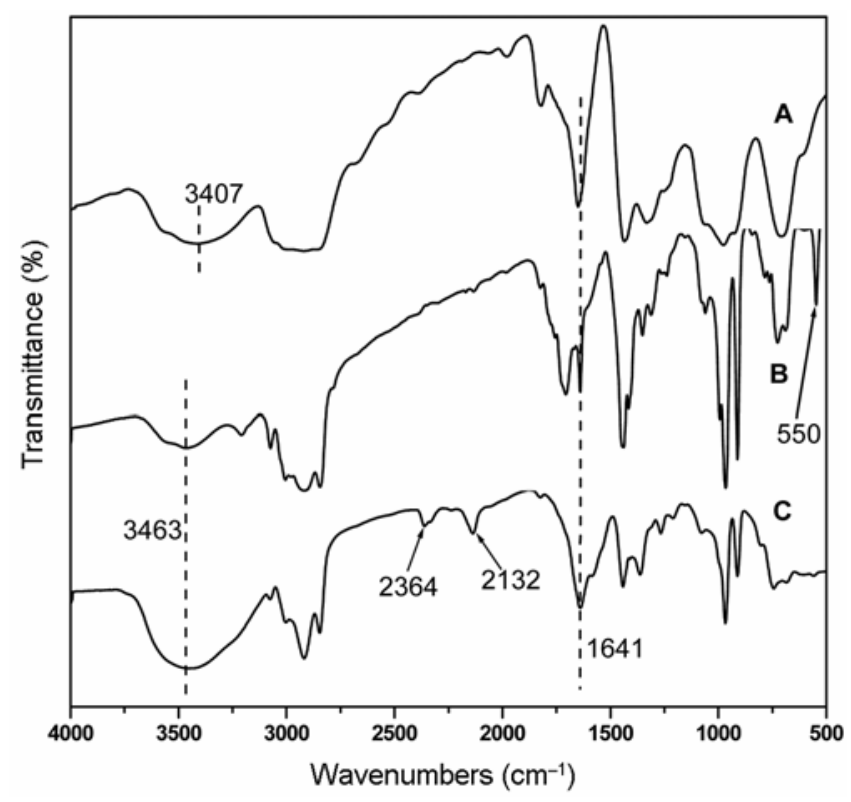

Figure 1. FT-IR spectra of the (A) HTPB (B) HTPB-CYC and (C) HTPB-DT. 
Table 1. Various characteristic data of the HTPB and the modified HTPB compounds

\begin{tabular}{lccc}
\hline Various characteristics & HTPB & HTPB-CYC & HTPB-DT \\
\hline Number average molecular weight $\left(\bar{M}_{n}\right)$ & 5200 & 5600 & 5400 \\
Poly dispersity index (PDI) & 1.433 & 1.514 & 1.533 \\
Viscosity (cp) at room temperature $\left(27^{\circ} \mathrm{C}\right)$ & 1480 & 1765 & 2360 \\
Hydroxyl value (mg KOH/g) & 43 & $40 \cdot 61$ & 39.5 \\
Microstructure* (\%) (cis, trans, vinyl) & $27,69,4$ & $24,69,7$ & $24,69,7$ \\
\hline
\end{tabular}

*Calculated from ${ }^{1} \mathrm{H}-\mathrm{NMR}$ spectra

hydroxyl groups are essential because these free $\mathrm{OH}$ groups need to be used for the propellant formulation, where $\mathrm{OH}$ groups react with isocyanides to form polyurethane. The ${ }^{1} \mathrm{H}-\mathrm{NMR}$ spectra of HTPB, HTPB-CYC and HTPB-DT compound along with the chemical structures and peak assignments are presented in the figure 2. The chemical shift regions of the HTPB-CYC and HTPB-DT compound at $\delta=1 \cdot 2-1 \cdot 4,2-2 \cdot 1$ and $4.9-5 \cdot 4$ are exactly identical with the parent HTPB (Zymonas et al 1973; Quack and Fetters 1978). This reveals that in the HTPBCYC and HTPB-DT samples, the microstructure of HTPB is identical with the parent HTPB. The microstructure data calculated from ${ }^{1} \mathrm{H}-\mathrm{NMR}$ are presented in table 1. This data are also in agreement with our observation that the modification of HTPB backbone does not change the microstructure of HTPB. ${ }^{13} \mathrm{C}-\mathrm{NMR}$ spectra of the HTPB-CYC, HTPB-DT and the HTPB are also similar in nature (figure 3 ). The peaks in the $\delta 25-43$ region corresponds to aliphatic carbons of HTPB and the peaks at $\delta$ 114-142 region belong to olefinic carbons of HTPB (Kanakavel 1987). Thus, we can summarize that FT-IR, ${ }^{1} \mathrm{H}-\mathrm{NMR}$ and ${ }^{13} \mathrm{C}$-NMR analysis demonstrate the covalent attachment of CYC and the further modification to azide moiety is successful without disturbing the microstructure, other essential and unique physico-chemical properties of HTPB

\subsection{Proposed mechanism for the terminal functionalization of $H T P B$}

The proposed reaction mechanism for the modification of HTPB backbone is presented in scheme 3 . The protons from the terminal OH of the HTPB are attracted by the strong base $(\mathrm{NaH})$ and generate oxy anions at the terminal ends of the HTPB. These oxy anions are not very stable. Hence the oxy anions are easily converted to allyl anions by attracting protons from the neighboring carbon atoms. The long conjugation of the HTPB backbone helps to get the stabilization of the ally anions. Therefore, the terminal carbons of HTPB act as nucleophile. Because of the presence of nitrogen atoms in the CYC molecule the $\mathrm{Cl}^{-}$groups of CYC act as very good leaving group. Hence, the CYC molecule can easily attach at the two ends of the HTPB. Further reaction with $\mathrm{NaN}_{3}$ substitutes the $\mathrm{Cl}^{-}$groups from the CYC moiety and results in the HTPB-DT molecule. We have proposed this mechanism based on our analysis of GPC and FT-IR data. Similar type of reaction mechanism has been proposed by us in our earlier studies of the HTPB modification by DNCB molecule (Muralisankar et al 2009a, b). Figure 4 shows the GPC traces of the HTPB and the modified HTPB samples. All the traces are look alike. The absence of any peak owing to the small molecule in the GPC traces (figure 4) indicates that the CYC and CDT molecules are covalently attached with the HTPB. The calculated number average molecular weight $\bar{M}_{\mathrm{n}}$ from the GPC traces and the polydispersity index (PDI) are presented in table 1. A little increase of $\bar{M}_{\mathrm{n}}$ value in case of modified HTPB samples, similar GPC traces and identical PDI attribute that the CYC molecule covalently attach to the HTPB without destroying the HTPB structure.

Our FT-IR, NMR and hydroxyl values discussed in the previous section clearly prove the presence of free $\mathrm{OH}$ at the two terminals of the HTPB and double bond in the HTPB backbone. We have carried out systematic deuterium exchange proton NMR studies to confirm the presence of free terminal hydroxyl groups in the modified HTPB. Figure 5 shows the proton NMR spectra of the HTPB-DT sample in various deuterium solvents. Spectrum A in figure 5 was recorded in $\mathrm{CDCl}_{3}$ solvent and the peaks are shown in the figure. The chemical shift at $\delta=1.62$ with integration for two hydrogens corresponds to the hydrogens of the hydroxyl groups of the HTPB (Amador et al 2002). We have recorded spectrum B after addition of $\mathrm{D}_{2} \mathrm{O}$ to spectrum $\mathrm{A}$ solution. The chemical shift at $\delta=1.62$ corresponding to the hydroxyl groups completely disappeared in spectrum $B$ indicating the successful exchange of deuterium between the solvent $\mathrm{D}_{2} \mathrm{O}$ and HTPB. We have also recorded spectrum $\mathrm{C}$ by adding $\mathrm{CD}_{3} \mathrm{OD}$ in the spectrum A solution. Spectrum $\mathrm{C}$ shows the appearance of a new chemical shift at $\delta=4.23$ in addition to the disappearance of chemical shift at $\delta=1.62$ for the hydroxyl groups of HTPB. This new chemical shift at $\delta=4.23$ corresponds to the $\mathrm{OH}$ of $\mathrm{CD}_{3} \mathrm{OH}$ which results from the deuterium exchange between the solvent $\mathrm{CD}_{3} \mathrm{OD}$ and the hydroxyl groups of the HTPB. We mixed $\mathrm{CDCl}_{3}$ and $\mathrm{CD}_{3} \mathrm{OD}$ solvents in the same proportion as it was in case of spectrum $\mathrm{C}$, and proton NMR spectrum was recorded and is shown in the inset of figure 5. The 


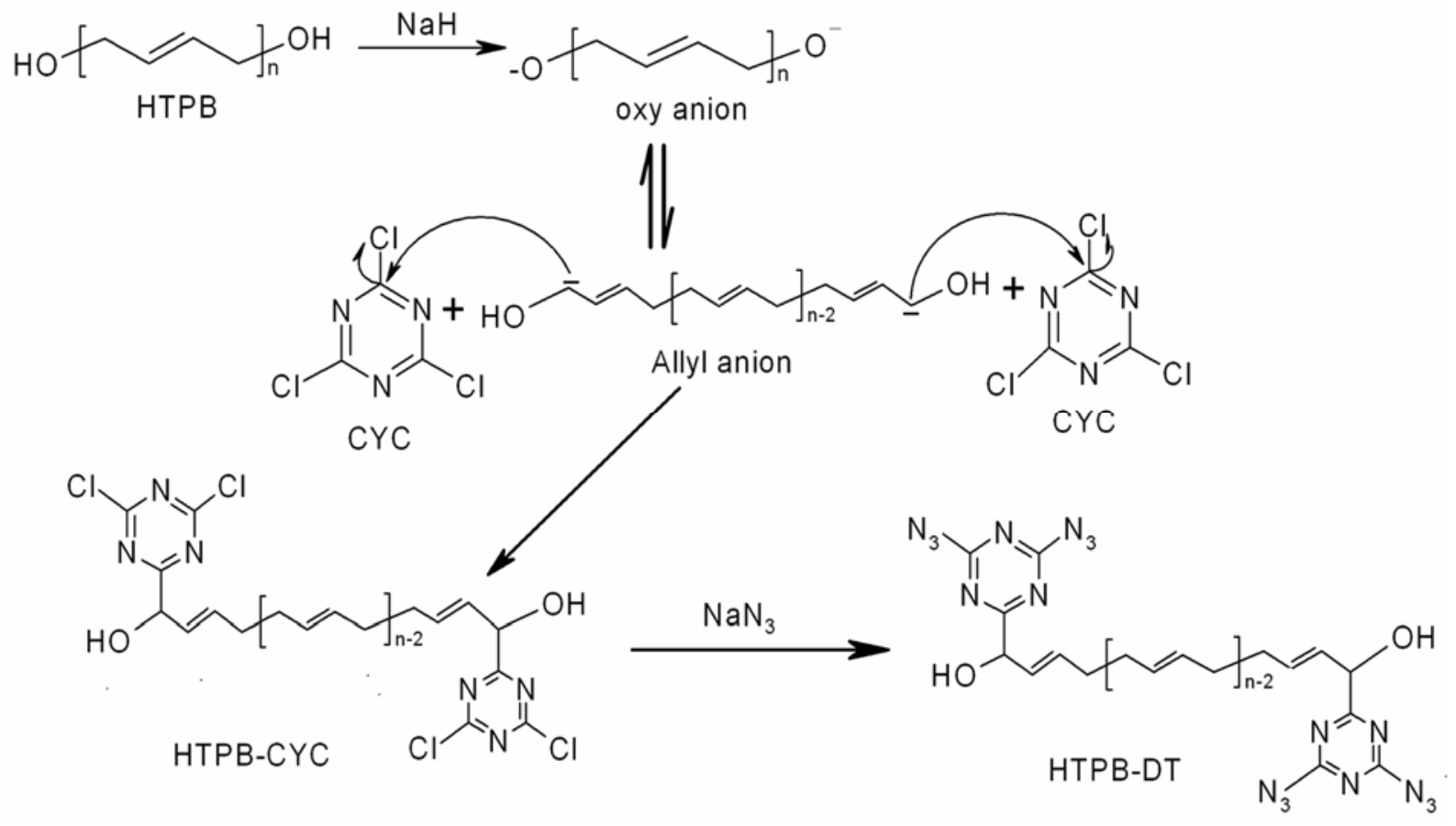

Scheme 3. Proposed mechanism for the terminal functionalization of HTPB by polyazido nitrogen rich molecules.

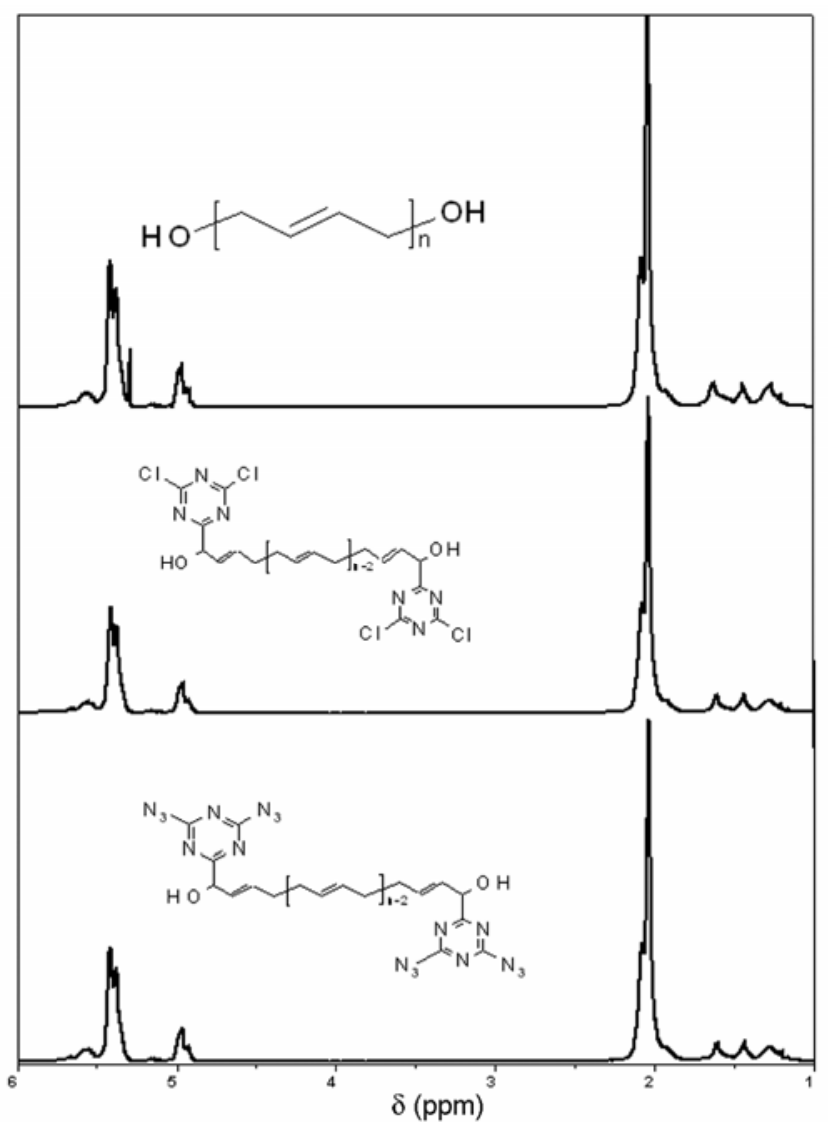

Figure 2. Proton NMR spectra of HTPB, HTPB-CYC and HTPB-DT. Spectra are recorded using $\mathrm{CDCl}_{3}$ as a NMR solvent. peak at $\delta=3.78$ is due to deuterium exchange between the $\mathrm{CD}_{3} \mathrm{OD}$ and moisture present in the solvents as trace impurity (Hugo et al 1997). This result ensures that the new chemical shift at $\delta=4.23$ present in spectrum $C$ is exclusively due to the exchange reaction between $\mathrm{CD}_{3} \mathrm{OD}$ and the $\mathrm{OH}$ groups of HTPB. Hence the disappearance of the chemical shift at $\delta=1.62$ and appearance at $\delta=4.23$ clearly proves the deuterium exchange between the solvent and the HTPB. Therefore, the above NMR studies undoubtedly demonstrate and suggest the existence of the free terminal hydroxyl groups in the modified HTPB (HTPB-DT). Our proposed mechanism (scheme 3) suggests the attachment of the CYC molecules at the two terminal carbon atoms of the HTPB chain. However, the obvious question that arises is what is the proof of the terminal attachment of the CYC molecule as presented in the scheme 3. We have analysed FT-IR spectra (figure 6) of the HTPB and the modified HTPB samples very closely to prove our terminal attachment chemistry. The terminal OH of the HTPB shows stretching at $3407 \mathrm{~cm}^{-1}$ which is much lower than the expected stretching of the free $\mathrm{OH}$ at $3600 \mathrm{~cm}^{-1}$ (Silverstein and Webster 2002). This reveals that in the HTPB a strong intermolecular hydrogen bonding between the $\mathrm{OH}$ groups of different polymer chains exist. Surprisingly, the HTPB-CYC and HTPB-DT samples show $\mathrm{OH}$ stretching at $3463 \mathrm{~cm}^{-1}$ (figure 6). This indicates that $\mathrm{CYC}$ and $\mathrm{CDT}$ molecule are able to break the intermolecular hydrogen bonding between the terminal hydroxyl of the HTPB chains and as a result $\mathrm{OH}$ stretching for the modified HTPB is observed 
at a higher wavenumber than the parent HTPB. It is important to note that the $\mathrm{OH}$ stretching frequency of HTPB-CYC and HTPB-DT have not shifted completely to the expected stretching of the free $\mathrm{OH}$ at $3600 \mathrm{~cm}^{-1}$ instead it shifts only to $56 \mathrm{~cm}^{-1}$ a higher wave number compared to the parent HTPB. This attributes the formation of hydrogen bonding between the $\mathrm{OH}$ groups of the HTPB and the CYC or CDT molecules. The hydrogen bonding between the terminal $\mathrm{OH}$ and the nitrogen atom of triazine ring is possible. The possibility of hydrogen bonding between the $\mathrm{OH}$ and the $\mathrm{Cl} / \mathrm{N}_{3}$ has been ruled out since $\mathrm{Cl} / \mathrm{N}_{3}$ is far away from the $\mathrm{OH}$ group. Because of this hydrogen bonding the $\mathrm{OH}$ frequency in case of modified HTPB samples move to $3463 \mathrm{~cm}^{-1}$ and not to $3600 \mathrm{~cm}^{-1}$. Thus the existence of the hydrogen bonding between terminal $\mathrm{OH}$ and $\mathrm{N}$ and breaking of intermolecular
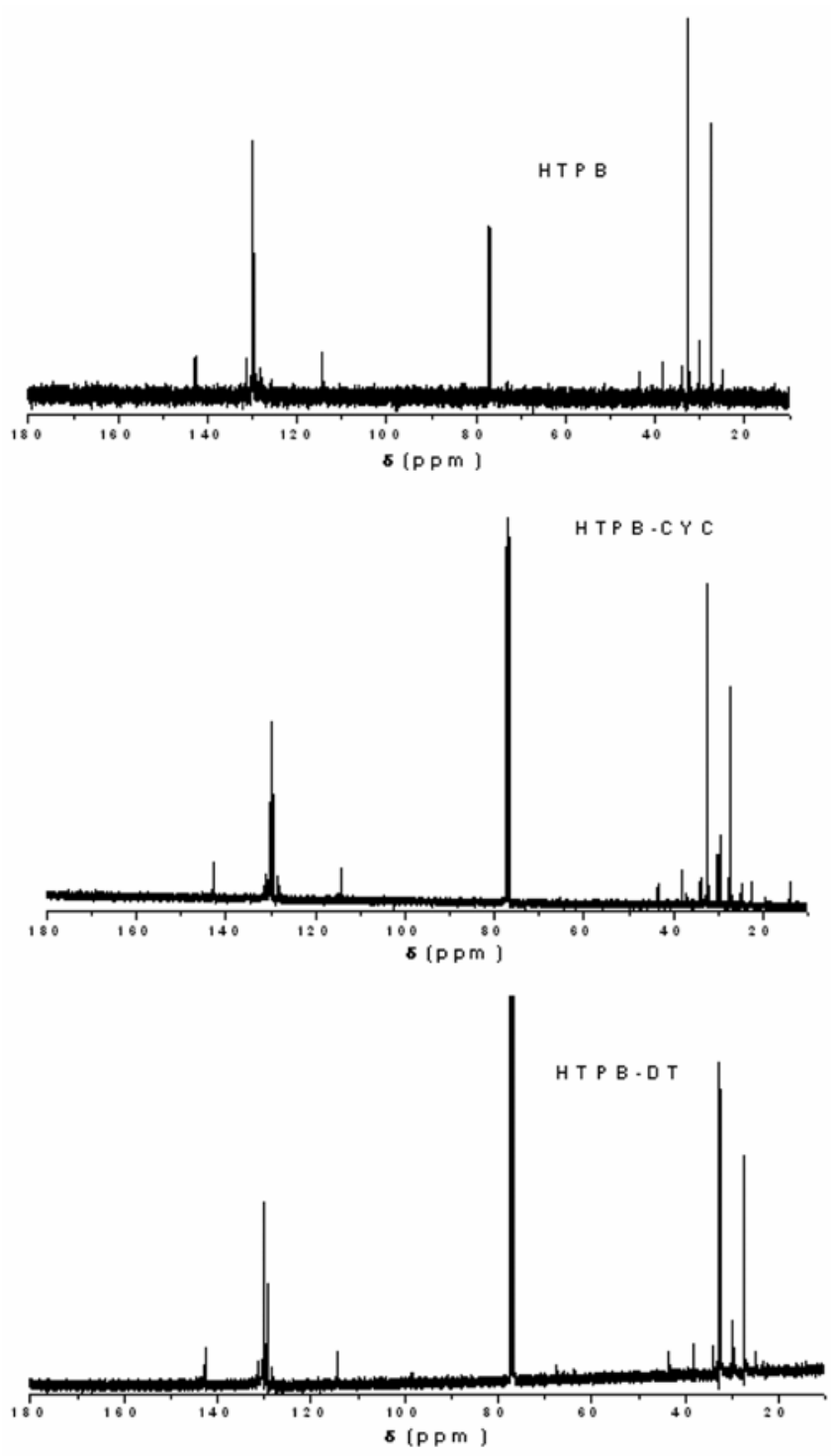

Figure 3. ${ }^{13} \mathrm{C}-\mathrm{NMR}$ spectra of $\mathrm{HTPB}, \mathrm{HTPB}-\mathrm{CYC}$ and HTPB-DT. $\mathrm{CDCl}_{3}$ are used as a NMR solvent. hydrogen bonding of HTPB chains are proved from the IR study. Therefore, for successful hydrogen bonding

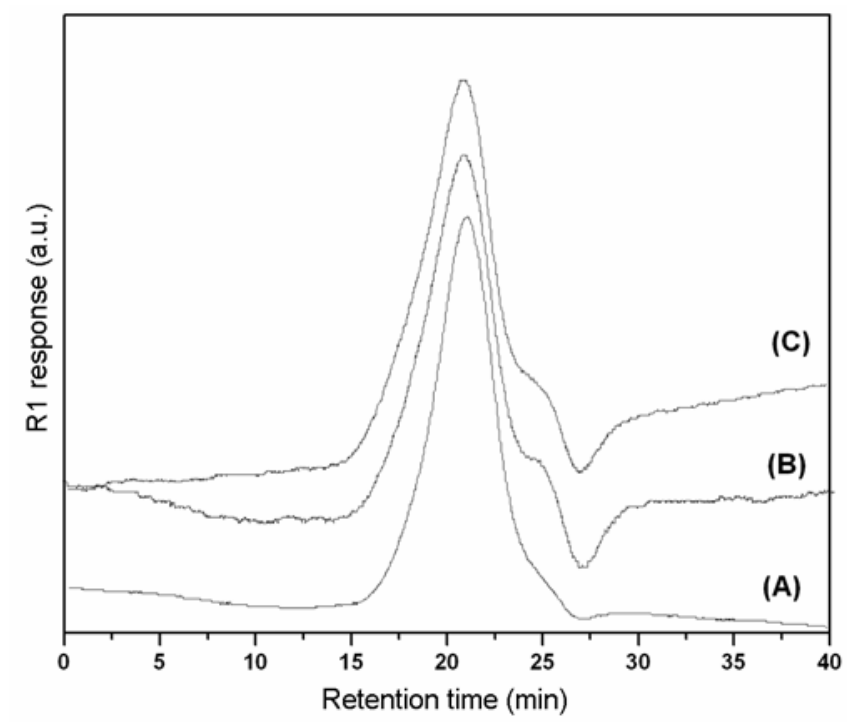

Figure 4. Gel permeable chromatograph of the (A) HTPB (B) HTPB-CYC and (C) HTPB-DT.

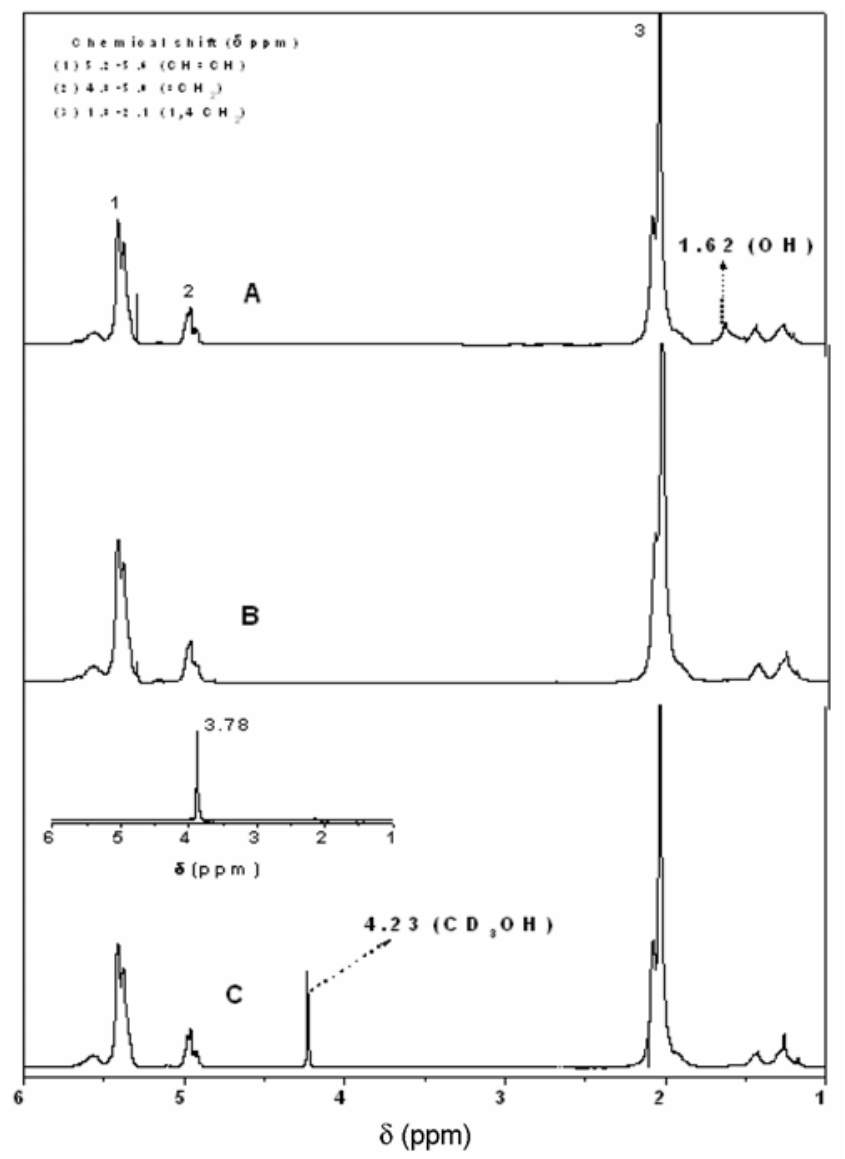

Figure 5. Deuterium exchange proton NMR studies of modified $\mathrm{HTPB}$ in various solvents (A) $\mathrm{HTPB}-\mathrm{DT}-\mathrm{CDCl}_{3}$ (B) HTPB-DT-CDCl ${ }_{3}-\mathrm{D}_{2} \mathrm{O}$ (C) HTPB-DT-CDCl ${ }_{3}-\mathrm{CD}_{3} \mathrm{OD}$ and inset mixture of solvents $\left(\mathrm{CDCl}_{3}-\mathrm{CD}_{3} \mathrm{OD}\right)$. 
between $\mathrm{N}$ and $\mathrm{OH}$; the $\mathrm{CYC}$ molecules have to be in the adjacent carbon atoms of the $\mathrm{OH}$ groups. Thus the terminal attachments of the CYC molecules are expected and obvious. Hence our proposed mechanism given in the scheme 3 is justified. Our theoretical calculation (discussed later) also shows the efficient hydrogen bonding between $\mathrm{OH}$ of HTPB and $\mathrm{N}$ atom of the triazine ring.

\subsection{Absorption spectroscopy}

The electronic absorption spectra of HTPB, CYC, HTPBCYC and HTPB-DT compounds are recorded from their

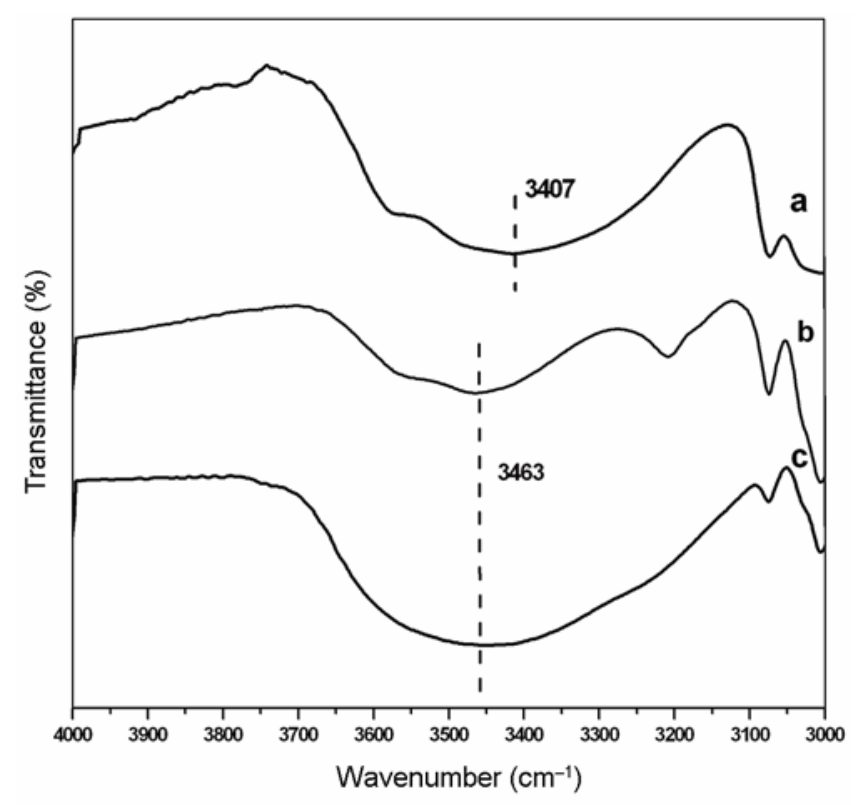

Figure 6. FT-IR spectra of (a) HTPB, (b) HTPB-CYC and (c) HTPB-DT.

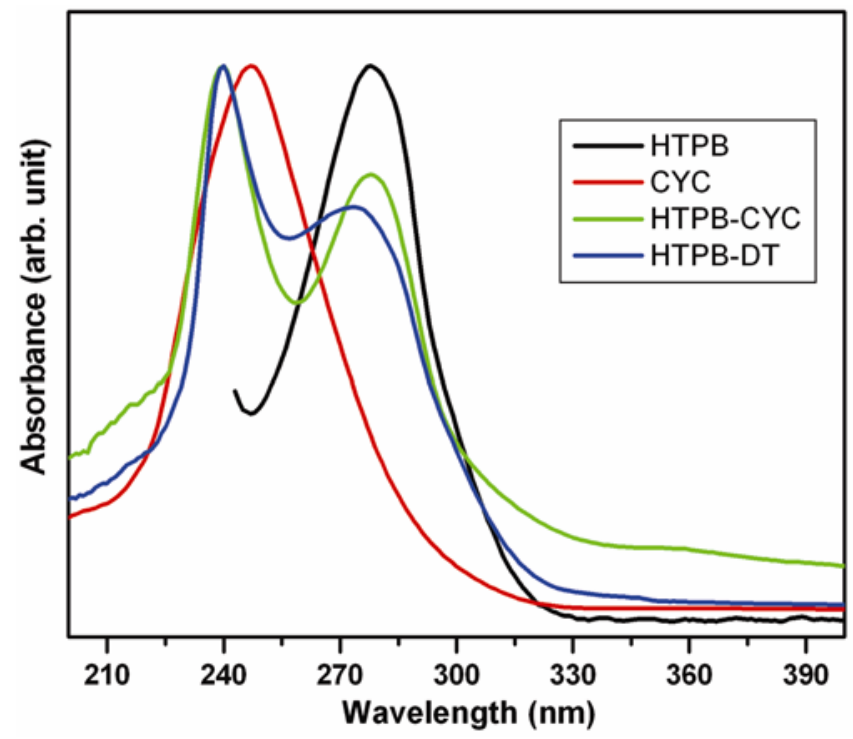

Figure 7. Absorption spectra of the HTPB, HTPB-CYC, HTPB-DT and CYC from their dilute solution in THF. dilute solution in THF solvent and is shown in figure 7. The absorption peak at $280 \mathrm{~nm}$ in case of HTPB is due to the $\pi \rightarrow \pi^{*}$ transition of trans microstructure of HTPB. CYC molecule has a sharp distinct peak at $247 \mathrm{~nm}$. HTPB-CYC shows two distinct sharp peaks at $239 \mathrm{~nm}$ and $280 \mathrm{~nm}$, the HTPB-DT also shows two distinct peaks at 239 and $273 \mathrm{~nm}$. The peaks at 273 and $280 \mathrm{~nm}$ in the HTPB-DT and HTPB-CYC respectively, correspond to the $\pi \rightarrow \pi^{*}$ transition of trans microstructure of the HTPB. The peaks at $239 \mathrm{~nm}$ in HTPB-CYC and HTPBDT are due to triazine rings. Therefore, the existence of both triazine and HTPB absorption peaks in the modified samples prove that the modification of HTPB backbone is successful. The $\pi \rightarrow \pi^{*}$ transition of HTPB backbone has been blue shifted from $280 \mathrm{~nm}$ to $273 \mathrm{~nm}$ in HTPB-DT compounds. This blue shift is due to the azide functional groups present in the triazine ring of the CDT molecule. Because of these azides, the triazine rings are more electron rich in nature which perturbs the conjugation of HTPB back bone and as a result the blue shift of the

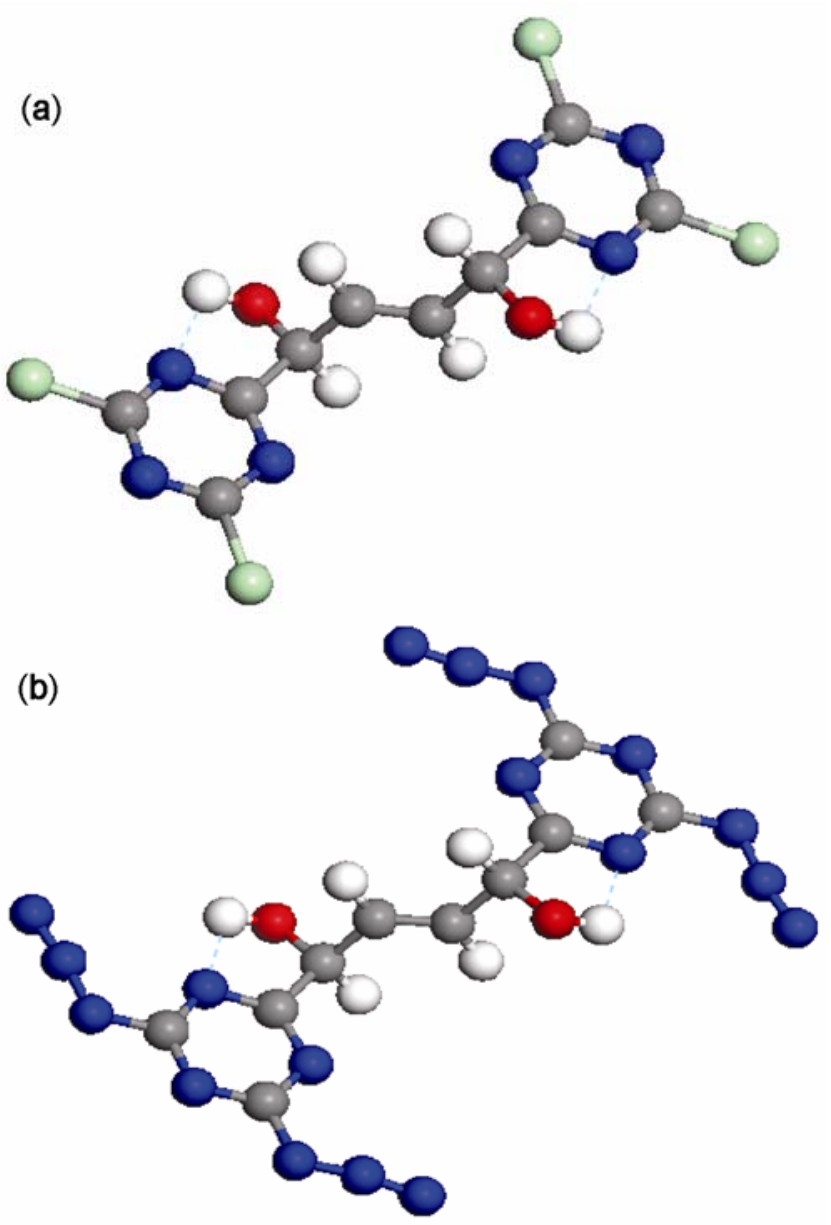

Figure 8. Energy minimized stable structure of the (A) HTPB-CYC and (B) HTPB-DT. Energy minimization was carried out considering single repeat unit. Structure shows the presence of trans conformation and hydrogen bonding (dotted line). 
Table 2. Detonation performance data

\begin{tabular}{lcccc}
\hline Molecule & Density $(\mathrm{g} / \mathrm{cc})$ & $\begin{array}{c}\text { Detonation } \\
\text { pressure }(\mathrm{GPa})\end{array}$ & $\begin{array}{c}\text { Velocity of } \\
\text { detonation }(\mathrm{km} / \mathrm{s})\end{array}$ & $\begin{array}{c}\text { Heat of formation } \\
(\mathrm{kJ} / \mathrm{mol})\end{array}$ \\
\hline CDT & 1.64 & 21.75 & 7.21 & $1085 \cdot 82$ \\
HTPB-CDT & 1.47 & 18.13 & 6.82 & 1916.37 \\
TNT & 1.64 & 19.78 & 6.90 & - \\
\hline
\end{tabular}

$\pi \rightarrow \pi^{*}$ takes place. Figure 7 also shows that the absorption of triazine ring is also blue shifted from $247 \mathrm{~nm}$ to $239 \mathrm{~nm}$ in both the cases. This is also due to the reason discussed above. These observations once again provide evidence for the existence of covalent linkage between the CYC and the HTPB.

\subsection{Theoretical calculation}

Theoretical calculations were carried out on the CDT and the HTPB-DT molecules to look into their potential as energetic materials. Various parameters such as density, detonation pressure $\left(P_{\mathrm{D}}\right)$ and velocity of detonation (VOD) of these molecules were calculated and are presented in table 2. Detonation data for trinitrotoluene (TNT) is also listed in table 2 for comparison. We have considered only one repeat unit of HTPB with two CDT molecules attached to the terminal carbon atoms for the simplicity of the calculation in case of HTPB-DT. Figure 8 represents the energy minimized structure of the HTPB-CYC and HTPB-DT. The presence of trans conformer of HTPB and hydrogen bonding between the nitrogen of triazine ring and OH group of HTPB in both the compounds are clearly visible in the energy minimized structure shown in figure 8 . Hence, both, our theoretical calculation and experimental results obtained from IR, NMR and UV are matching well and suggest the presence of hydrogen bonding and trans microstructure in the modified HTPB. Table 2 data reveals that the density of CDT is similar to TNT and HTPB-DT density is comparable with TNT. The detonation performance and velocity of detonation of CDT is better than TNT. This observation prompted us to attach this molecule on the HTPB backbone. The velocities of detonation and detonation pressure of HTPB-DT are comparable with TNT. The detonation performance data of HTPB-DT are not as good as CDT or TNT. However, it is important to remember that the HTPB-DT compound is meant for binder application only. The extra energy supplied by this to the propellant system would be added energy to the system. Therefore we can certainly conclude that the HTPB-DT would be an energetic binder.

\section{Conclusions}

Polyazido nitrogen rich molecules have covalently attached at the terminal carbon atoms of the HTPB with- out destroying the unique physico-chemical properties such as fluidity, microstructure, etc. of the parent HTPB. The disruption of the intermolecular hydrogen bonding between the HTPB chains and the formation of hydrogen bonding between the terminal $\mathrm{OH}$ group of the HTPB and the $\mathrm{N}$ atom of the triazine ring are the driving forces for the covalent attachment of polyazido molecule at the terminal carbon atoms of the HTPB. The $\pi$ electron delocalization of the butadiene backbone has perturbed after the modification. Theoretical study shows that the HTPBDT has moderate detonation property. In summary, our HTPB-DT may be suitable for its application as a promising energetic binder in solid rocket propellants and will enhance the energetic characteristics of the propellant.

\section{Acknowledgements}

We gratefully acknowledge the financial support by the Advanced Center for Research in High Energy Materials (ACRHEM), University of Hyderabad. We thank Mr G M Gore of HEMRL, Pune, India for giving us the HTPB sample. We are thankful to Prof M Durgaprasad and Dr $\mathrm{R}$ Nagarajan for helping us with theoretical and NMR studies, respectively.

\section{References}

Amador M, Ariza X, Garcia J and Sevilla S 2002 Organic Letts. 254511

Becke A D 1993 J Chem. Phys. 985648

Bohn M A and Elsner P 1999 Propellants, explosives, pyrotechnics 24199

Chen S H, Yu K C, Houng S L and Lai J Y 2000 J Membrane Sci 17399

Desai H J, Cunliffe A V, Millar R W, Paul N C, Stewart M J and Amass A J 1996 Polymer 373471

Eroglu M S, Hazer B and Guven O 1996 Polymer Bull. 36695

Frisch M J 2003 Gaussian 03, Revision B.05, Gaussian, Inc. (Pittsburgh, PA)

Gaur B, Lochab B, Choudhary V and Verma I K 2003 J Macromol. Sci. Part-C C43505

Golding P, Millar R W, Paul N C and Richards D H 1988 Tetrahedron Lett. 292731

Gupta T, Pradhan N C and Adhikari B 2002 Bull. Mater. Sci. 25 533

Hardwood H J 1982 Rubber Chem. Tech. 55769

Hugo E G, Kotlyar V and Nudelman A 1997 J. Org. Chem. 62 7512 
Huynh My-H V, Hiskey M A, Hartline E L, Montoya D P and Gilardi R 2004 Angew. Chem. Int. Ed. 434928 and references there in

Kanakavel M 1987 Makromol. Chem. 188845

Kit B and Evered D S 1960 Rocket propellant handbook (New York: The Macmillan Company)

Kuo C, Samuelson, L A, McCarthy S P, Tripathy S K and Kumar J 2003 J Macromolecular Sci. Part A. Pure Appl. Chem. A40 1383

Lee C, Yang W and Parr R G 1988 Phys Rev. B37 785

Manjari R, Joseph V C, Pandureng L P and Sriram T 1993 J. Appl. Polym. Sci. 48271

Mathieu J and Stucki H 2004 Chimia 58383

Meyers G E and Baumgarter W E 1973 US Nat. Tech. Infor. Ser. (NTIS) AD report No. 760579

Millett J C F, Bourne N K and Akhavan J 2004 J. Appl. Phys. 954722

Millett J C F and Bourne N K 2004 J. Phys. D: Appl. Phys. 37 2901

Muralisankar R, Roy T K and Jana T 2009a J. Appl. Polym. Sci. 114732

Muralisankar R, Saha S, Meera, K S and Jana T 2009b Bull. Mater. Sci. 32507

Murray G E and Purves C B 1940 J. Am. Chem. Soc. 623194
Muthiah R M, Manjari R., Krishnamoorthy V N and Gupta B R 1991 Polym. Eng. Sci. 3161

Nazare A N, Deuskar V D, Asthana S N and Shrotri P G 1993 J. Polym. Mater. 10213

Paul N C 1997 Modern explosives and nitration technique: explosives in the service of man (eds) JE Dolan and S S Langer, (Cambridge: Royal Society of Chemistry) pp. 79-91.

Ogg C J, Porter W L and Willits C O 1945 Ind. Eng. Chem. Anal. Edn. 17344

Quack G and Fetters L J 1978 Macromolecules 11369

Silverstein R M and Webster FX 2002 Spectroscopic identification of organic compounds (New York: John Wiley \& Sons)

Subramanian K and Sastri K S 2003 J. Appl. Polym. Sci. 90 2813

Subramanian K 1999 Europ. Polym. J. 351403

Urbanski T 1984 Chemistry and technology of explosives (Pergamon Press, New York) Vol. IV

Vandenberg E J 1972 U.S. Pat. 3 645: 917

Yang J M and Lin H T 2001 J. Membrane Sci. 187159

Ye C, Gard G L, Winter R W, Syvret R G, Twamley B and Shreeve J M 2007 Org. Lett. 93841

Zymonas J, Santee E R and Harwood H J 1973 Macromolecules 6129 